Conclusion AFI reduces time to detection in novice endoscopists and could be a valuable training tool for trainees to improve their skills in detecting dysplasa in a time efficient manner. Advanced imaging endoscopic techniques may therefore help trainee endoscopists more than experienced endoscopists. Disclosure of Interest None Declared.

\section{PWE-047 WHEN SHOULD I TAKE TERMINAL ILEAL BIOPSIES? EXPERIENCE FROM A SINGLE UNIT}

${ }^{1,2} \amalg$ Neilson*, ${ }^{1,2} \mathrm{R}$ Bevan, ${ }^{1,2,3} \mathrm{CJ}$ Rees. 'South Tyneside District Hospital, South Shields, UK; ${ }^{2}$ Northern Region Endoscopy Group, Newcastle, UK; ${ }^{3}$ School of Medicine, Pharmacy and Health, Durham University, Stockton-on-Tees, UK

\subsection{6/gutjnl-2014-307263.307}

Introduction Terminal ileum (TI) intubation at colonoscopy may be useful in the investigation of patients with diarrhoea or possible inflammatory bowel disease (IBD). ${ }^{1,2}$ The yield of TI biopsies is variable and there are no standards for current practice. ${ }^{2,3}$ Furthermore, in the UK concerns remain regarding the potential for prion transmission.

Methods We aim to establish the yield of TI biopsies in a single unit. All TI biopsies recorded on the pathology system in a 3year period were reviewed. Colonoscopy reports and case notes were reviewed to establish if biopsy results were clinically relevant (defined as altering management). Statistical analysis was performed using SPSS. P values were calculated using Fisher's exact test to show any difference in biopsy yield between normal and abnormal looking mucosa for each indication. The values were calculated for all abnormal biopsy results and clinically relevant biopsy results.

Results 129 TI biopsies were taken between September 2010 and September 2013, 49 (38\%) male and 80 (62\%) female. Mean age 44 years (s.d. 17.2). There were 29 (22.5\%) cases of known IBD. 5 (3.9\%) cases were completion colonoscopies after colorectal cancer surgery where TI biopsies are taken to prove a complete examination.

Conclusion We demonstrate that when investigating patients with diarrhoea, abdominal pain or IBD, if the terminal ileum is visually normal, biopsies do not add to the clinical picture. There is a higher yield of relevant biopsy abnormalities when the TI appears abnormal. We can recommend within our practice that visual assessment of a normal terminal ileum is adequate, thereby reducing unnecessary biopsies. This reduces the workload for pathology laboratories, reduces risk from biopsies and improves patient care as normal results can be communicated sooner to the patient.

\section{REFERENCES}

1 Morini $S$, et al. Retrograde ileoscopy in chronic nonbloody diarrhea: a porspective, case-control study. Am J Gastroenterol 2003;98(7):1512-15

2 Geboes K, et al. Is ileoscopy with biopsy worthwhile in patients presenting with symptoms of inflammatory bowel disease? Am J Gastroenterol 1998;93(2):201206

3 Melton SD, et al. lleal biopsy:Clinical indications, endoscopic and histopathologic findings in 10,000 patients. Dig Liver Dis 2011;43(3):199-203

Disclosure of Interest None Declared.

\section{PWE-048 RECURRENCE RATES FOLLOWING PIECEMEAL RESECTION OF 2 CM ADENOMATOUS POLYPS}

${ }^{1} \mathrm{M}$ Harling ${ }^{*},{ }^{1} \mathrm{~K}$ Kandiah, ${ }^{2} \mathrm{Z}$ Tsiamoulos, ${ }^{1} \mathrm{G}$ Smith, ${ }^{2} \mathrm{~B}$ Saunders, IJ Martin. ${ }^{1}$ Gastroenterology Department, Imperial College Healthcare NHS Trust, London, UK; ${ }^{2}$ Wolfson Unit for Endoscopy, St Mark's Hospital, London, UK

\subsection{6/gutjnl-2014-307263.308}

Introduction Piecemeal endoscopic mucosal resection (pEMR) is a minimally invasive endoscopic technique for the resection of sessile/flat colorectal polyps (larger than $2 \mathrm{~cm}$ ). It has been suggested that patients should have a check procedure at 3 or 6 months to ensure complete initial excision of the lesion, and subsequent colonoscopic surveillance at between 1 and 3 years to identify recurrence.

Methods This is a retrospective observational audit, including all patients with sessile/flat colorectal polyps of more than $20 \mathrm{~mm}$ in diameter who underwent pEMR in 2010, across 4 London Teaching Hospitals. Patients were either local or tertiary referrals. Data was obtained from colonoscopy and histology reports. The primary outcome measured was the follow up rate at first, check colonoscopy ( 3 months, 6 months or 1 year), and at the subsequent surveillance colonoscopy (1, 2 or 3 years). Recurrence rate at both check and surveillance was a secondary outcome. A high-risk recurrence was considered to be more than or equal to $10 \mathrm{~mm}$ and a low-risk recurrence less than $10 \mathrm{~mm}$.

Results 153 patients were included in the cohort; 53 (34.6\%) patients were local referrals and $100(65.4 \%)$ were tertiary referrals. $128(83.6 \%)$ patients had a check colonoscopy and 74 patients $(49.0 \%)$ had a surveillance colonoscopy. Adenoma recurrence occurred in 44 (34.4\%) patients at check colonoscopy, with $3(2.4 \%)$ polyps having high-risk recurrence, and in 12 (16.3\%) patients at surveillance colonoscopy, with 3 (4.1\%)

\begin{tabular}{|c|c|c|c|c|c|c|c|}
\hline \multirow[t]{2}{*}{ Indication (n) } & \multicolumn{3}{|c|}{ Ileoscopy abnormal } & \multicolumn{3}{|c|}{ lleoscopy normal } & \multirow[t]{2}{*}{ P value (all/ clinically relevant) } \\
\hline & Number & Biopsy abnormal & Clinically relevant & Number & Biopsy abnormal & Clinically relevant & \\
\hline $\begin{array}{l}\text { Diarrhoea } \\
(67)\end{array}$ & 15 & 11 & 9 & 52 & 7 & 3 & $<0.001 /<0.001$ \\
\hline $\begin{array}{l}\text { Abdo pain } \\
\text { (39) }\end{array}$ & 12 & 9 & 8 & 27 & 3 & 2 & $<0.001 /<0.001$ \\
\hline $\begin{array}{l}\text { IBD assessment } \\
\text { (29) }\end{array}$ & 12 & 10 & 9 & 17 & 3 & 3 & $<0.001 / 0.006$ \\
\hline $\begin{array}{l}\text { Other* } \\
\text { (18) }\end{array}$ & 2 & 2 & 1 & 16 & 3 & 1 & $0.194 / 0.284$ \\
\hline $\begin{array}{l}\text { Total } \neq \\
(129)\end{array}$ & 34 & 25 & 21 & 95 & 14 & 1 & $<0.001 /<0.001$ \\
\hline
\end{tabular}

